\title{
Metaphorical Thinking and Information Processing Ability
}

\author{
Cittoor Girija Navaneedhan*, T. J. Kamalanabhan \\ Department of Management Studies, Indian Institute of Technology, Madras, India \\ Email: " girija.navaneedhan@gmail.com
}

Received 12 August 2014; revised 27 September 2014; accepted 12 October 2014

Copyright (C) 2014 by authors and Scientific Research Publishing Inc.

This work is licensed under the Creative Commons Attribution International License (CC BY). http://creativecommons.org/licenses/by/4.0/

c) (i) Open Access

\begin{abstract}
Practice of Metaphorical thinking in understanding given information promotes the communication of the two hemispheres by a bundle of connecting fibres, the corpus callosum at neo cortex level and through hippocampus at the level of limbic system. Hence, metaphorical thinking helps learners to make connections and develop patterns and relationships in parallel to the language as well as symbols relevant to the given information.
\end{abstract}

\section{Keywords}

Metaphorical Thinking, Corpus Callosum, Neo Cortex

\section{Introduction}

The two hemispheres of the brain of the cerebral cortex are linked by corpus callosum through which they communicate. Corpus callosum is the structure composed of millions of axons that have their dendrites and terminal buttons projecting in both right and left hemispheres. Metaphorical thinking initiates synaptic activity in the axons which in turn enhances co-ordination between right and left hemispheres of the brain. Krish Sathian [1] pointed out in a study that metaphor used in the textual message brings activation in the cerebral cortex enabling quick understanding of the information.

In general, the speed of neural information processing is a complex process which involves a variety of constraints, including the time for electrochemical signals to traverse axons and dendrites, axonal myelination, the diffusion time of neurotransmitters across the synaptic cleft, differences in synaptic efficacy, the coherence of neural firing, the current availability of neurotransmitters, and the prior history of neuronal firing. This procedure may vary from one individual to another. Danielle S. Bassett [2] pointed out that similar to computer chip performing a particular task human brain is also designed to perform a specific task depending on the biological development of the neurons. If the individuals are trained to think metaphorically, there is a probability of equa-

${ }^{*}$ Corresponding author. 
lising the speed of neural information processing. Figure 1 represents the teaching-learning model which explains how to initiate metaphorical thinking.

In this context, Human Brain and Computers are totally different from each other. To understand the function of the brain and computer, we need to look for analogy, problem solving ability and information processing ability being the components of metaphorical thinking. The following statements regarding the context (Human brain vs Computer) initiate Metaphorical thinking acting as stimulant to neurotransmitters across synaptic cleft.

Figure 2 reveals that practice of metaphorical thinking enhances the information processing ability and has been established by several research studies that corpus callosum play a fundamental role in integrating information and mediating complex behaviours "Leighton B. N. Hinkley [3]".

\section{The Role of Corpus Callosum in the Communication of Two Hemispheres of Cerebral Cortex}

Corpus collasum is band of nerve fibre which connects the left and the right hemispheres of the cerebral cortex. "Richard M. Restak [4]" a neurologist pointed out that left and right brain hemispheres are designed to handle certain specific tasks for e.g. Left hemisphere handles speech, language processing, logic reasoning, mathematical calculations, reading writing. Right hemisphere handles non verbal tasks such as copying designs, interpreting facial expressions, emotions. The right and the left brain in co-ordination perform several tasks of an individual in day today life. The corpus callosum is made up of white matter apart of the nerve cell through which transmission of signals between the two parts of the nerve cell takes place. The white matter of corpus callosum is considered as the highway by which electrical signals between a nerve cell body in one grey matter area travels to a nerve cell body in another grey matter area, something like a internet modem or your computer, while the white matter is the cable connecting the two. Therefore the white matter is essential for the transmission of signal between the nerve cells similar to a cable being important to get information from the computer which is connected to an internet modem. Figure 3 explains that by practicing metaphorical thinking the co-ordination between right and left hemispheres of cerebral cortex becomes harmonious as the time of signalling between two nerve cells become equal.

\section{Research Questions}

1) How seeking analogy helps in information processing ability?

2) How problem solving helps in information processing ability?

3) What is the impact of analogy and problem solving on information processing ability?

4) How metaphorical thinking influences information processing ability?

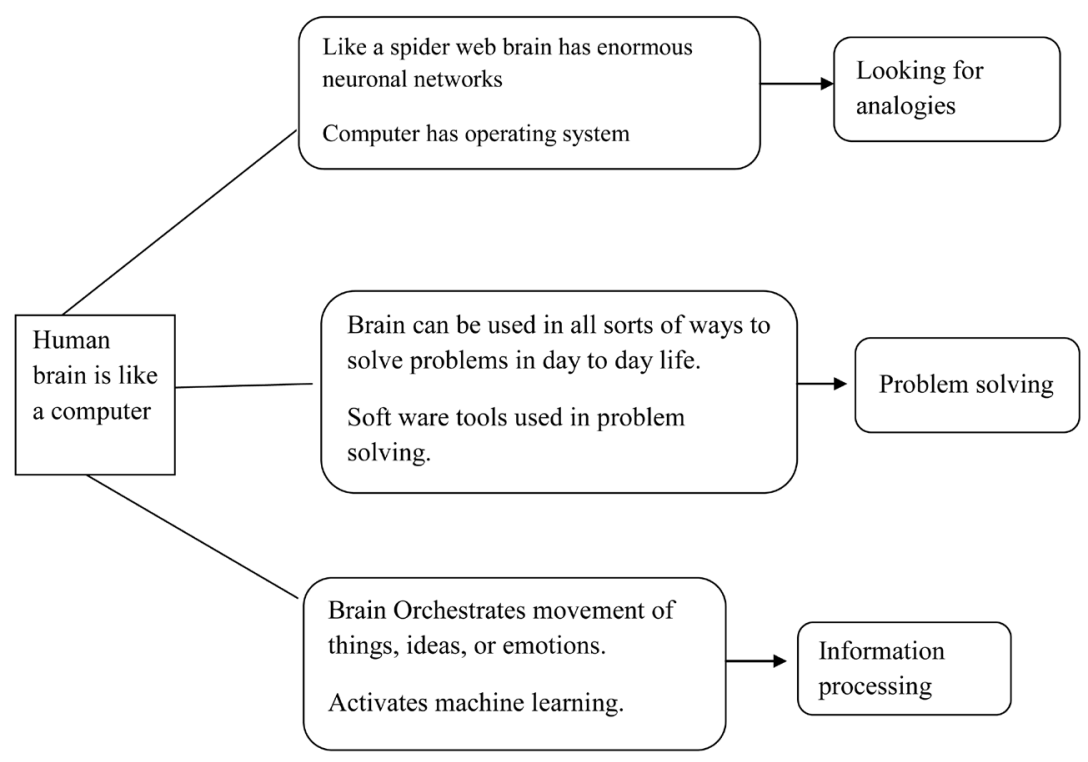

Figure 1. Teaching-learning model initiating Metaphorical thinking. 


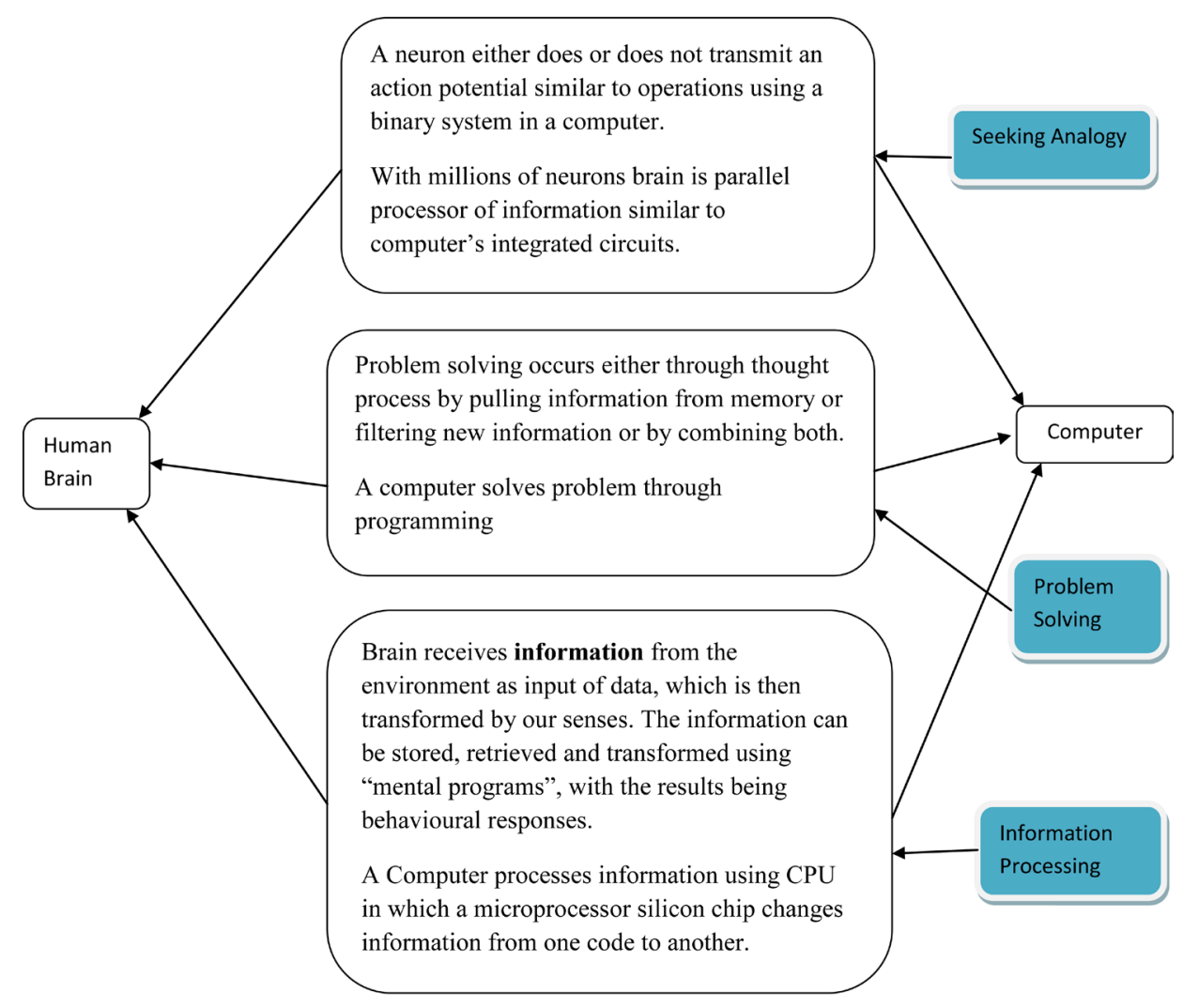

Figure 2. Model representing similarities between Human Brain and Computer.

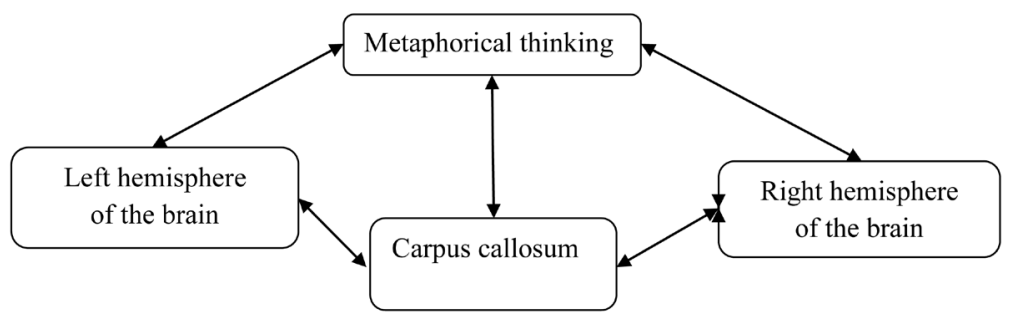

Figure 3. Model representing co-ordination between left and right hemispheres of brain.

\section{Hypotheses}

- There is no relationship between seeking analogy and information processing ability.

- Problem solving ability as well as information processing ability are independent of each other in an individual.

- Metaphorical thinking has no impact on information processing ability of an Individual.

\section{Methodology}

The experiment was carried out on 50 subjects (male (20) and female (30) teachers in the age group 25 to 40 years). The teachers are surveyed using Metaphorical thinking questionnaire consisting of 30 statements based on three components namely: 1) seeking analogy; 2) problem solving; 3) information processing ability. Metaphorical thinking questionnaire evaluates each of the three components consisting of 10 statements based on five point: Likert scale a), agree b), disagree c), strongly agree d), neither agree nor disagree and e) somewhat agree. The reliability of the questionnaire was calculated by using odd even method and the value was found to be 0.756. As the questionnaire was prepared by the author according to the present study it is not used in any other studies. Teachers were asked to read the statements carefully and tick any of the options according to their un- 
derstanding. The scores thus collected were subjected statistical analysis. For the calculation of regression analysis SPSS version 17.0 is used.

\section{Results}

Table 1 shows the result of the regression analysis. From the values, it is possible to predict that there is significant relationship between Metaphorical thinking with the three components mentioned. Hence, there is strong interlinking between the variables. $\mathrm{R}_{1.234}$ value for female sample was found to be greater than for male sample. It is attributed to the fact that the size of corpus callosum is $23 \%$ larger than the male counter parts.

\section{Discussion}

Recent research studies on Neuroscience have proved that the constituent parts of the brain take care of processing the information. e.g.:

Frontal lobe of cerebrum: The purpose and the strategy of the information

Amygdala: Motivates the action.

The Hippocampus: Manage the flow of key information.

Corpus callosum: Enable the communication from one sub system to another.

As it is very well known that corpus callosum has the largest bundle of nerve fibers in the brain, practice of metaphorical thinking stimulates both the hemispheres creating more synapses, to enable smooth processing of the information. "Ann Berthoff [5]" suggested that thinking is a mind function and interplay between the hemispheres. Metaphorical thinking initiates neuronal networks which are richly interconnected set of processors. Theses neurons, act as simple processors, with each neuron making a very small contribution to the overall processing of information. The following model in Figure 4 explains the relationship between metaphorical thinking, information processing ability as well as the role of corpus callosum.

"Brock and Fernette Eide [6]" supported the view that appropriate balance between the right and left brain hemispheres result in optimal thinking to produce effective communication and cooperation essential for problem solving, seeking analogy and processing the information regardless its nature.

Table 1. To show the relationship between seeking analogy, problem solving, information processing ability with metaphorical thinking and among male and female teachers.

\begin{tabular}{ccccccc}
\hline Variables & Gender & $\mathrm{N}$ & $\mathrm{R}_{1.23}$ & $\mathrm{R}_{1.24}$ & $\mathrm{R}_{1.34}$ & $\mathrm{R}_{1.234}$ \\
\hline $\begin{array}{c}\text { Metaphorical thinking vs Seeking analogy, } \\
\text { problem solving, information processing ability }\end{array}$ & Male & 20 & 0.383 & 0.464 & 0.525 \\
\hline
\end{tabular}

${ }^{*} p<0.05,{ }^{* *} p<0.01,{ }^{* * *} p<0.001$, N.S = NOT SIGNIFICANT. $\mathrm{R}_{1.23}=$ relationship between Metaphorical thinking vs seeking analogy and problem solving. $\mathrm{R}_{1.24}=$ relationship between Metaphorical thinking vs seeking analogy and information processing ability. $\mathrm{R}_{1.34}=$ relationship between Metaphorical thinking vs problem solving and information processing ability. $\mathrm{R}_{1.234}$ = relationship between Metaphorical thinking vs seeking analogy, problem solving and information processing ability.

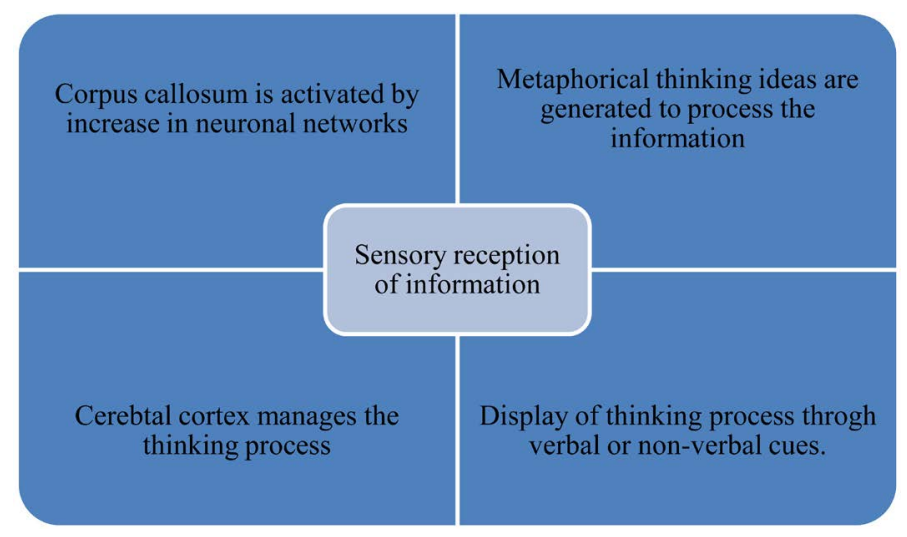

Figure 4. Model depicting the role of metaphorical thinking in information processing. 


\section{Conclusion}

Metaphorical thinking creates impact on information processing ability. So this technique enables individuals to possess concrete experience of the information. Metaphorical thinking helps individual in creative problem solving by "thinking outside the box" meaning helps in divergent thinking. Genter \& Genter [7] pointed out that Metaphorical thinking enables information processing ability by reflection and communication of complex topics. Corpus callosum with 250 million nerve fibres is a centre for transmission of neural data which connects two hemispheres that process higher order information with the process time lying in between 5 to $20 \mathrm{~ms}$ depending on synaptic signals. The activation of corpus callosum could be achieved by practicing metaphorical thinking. The results of the analysis indicates that the practice of Metaphorical thinking regularly in teaching learning process promotes information processing ability as there exists strong correlation between the components.

\section{References}

[1] Sathian, K., Lacey, S. and Stilla, R. (2012) Metaphorically Feeling: Comprehending Textural Metaphors Activates Somatosensory Cortex. Brain and Language, 2012.

[2] Bassett, D.S. and Green, D.L., Meyer-Lindenberg, A., Weinberger, D.R., Moore, S.W. and Bullmore, E.T. (2010) Efficient Physical Embedding of Topologically Complex Information Processing Networks in Brains and Computer Circuits. PLoS Computational Biology, 6, e1000748. http://dx.doi.org/10.1371/journal.pcbi.1000748

[3] Hinkley, L.B.N. (2012) The Role of Corpus Callosum Development in Functional Connectivity and Cognitive Processing. PLoS ONE, 7, e39804. http://dx.doi.org/10.1371/journal.pone.0039804

[4] Restak, R.M. (1995) Brainscapes: Newyork: Hyperion.

[5] Berthoff, A.E. (2013) The Making of Meaning: Metaphors, Models, and Maxims for Writing Teachers. Boynton/Cook Publishers, Montclair.

[6] Brock and Eide, F. (2004) New Horizons in Learning. John Hopkins University, Baltimore.

[7] Gentner, D. and Gentner, D.R. (1983) Flowing Waters and Teeming Crowds: Mental Models of Electricity. In: Gentner, D. and Stevens, A.L., Eds., Mental Models, Erlbaum, Hillsdale, 99-129. 
Scientific Research Publishing (SCIRP) is one of the largest Open Access journal publishers. It is currently publishing more than 200 open access, online, peer-reviewed journals covering a wide range of academic disciplines. SCIRP serves the worldwide academic communities and contributes to the progress and application of science with its publication.

Other selected journals from SCIRP are listed as below. Submit your manuscript to us via either submit@scirp.org or Online Submission Portal.
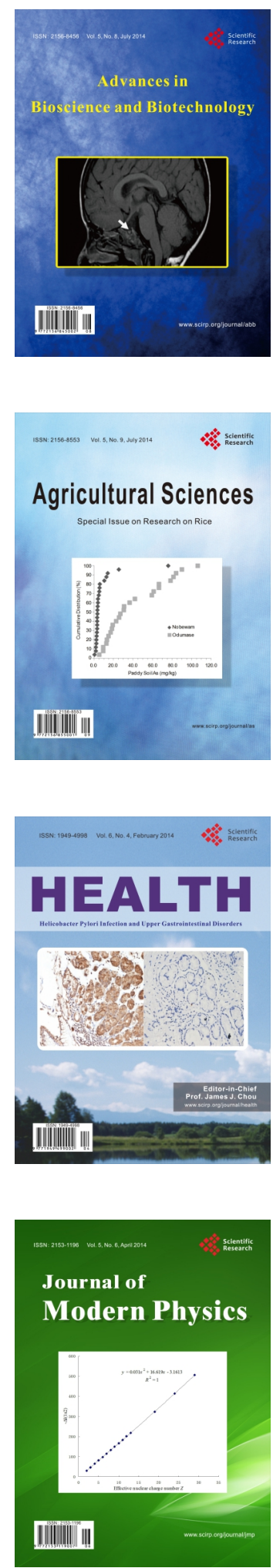
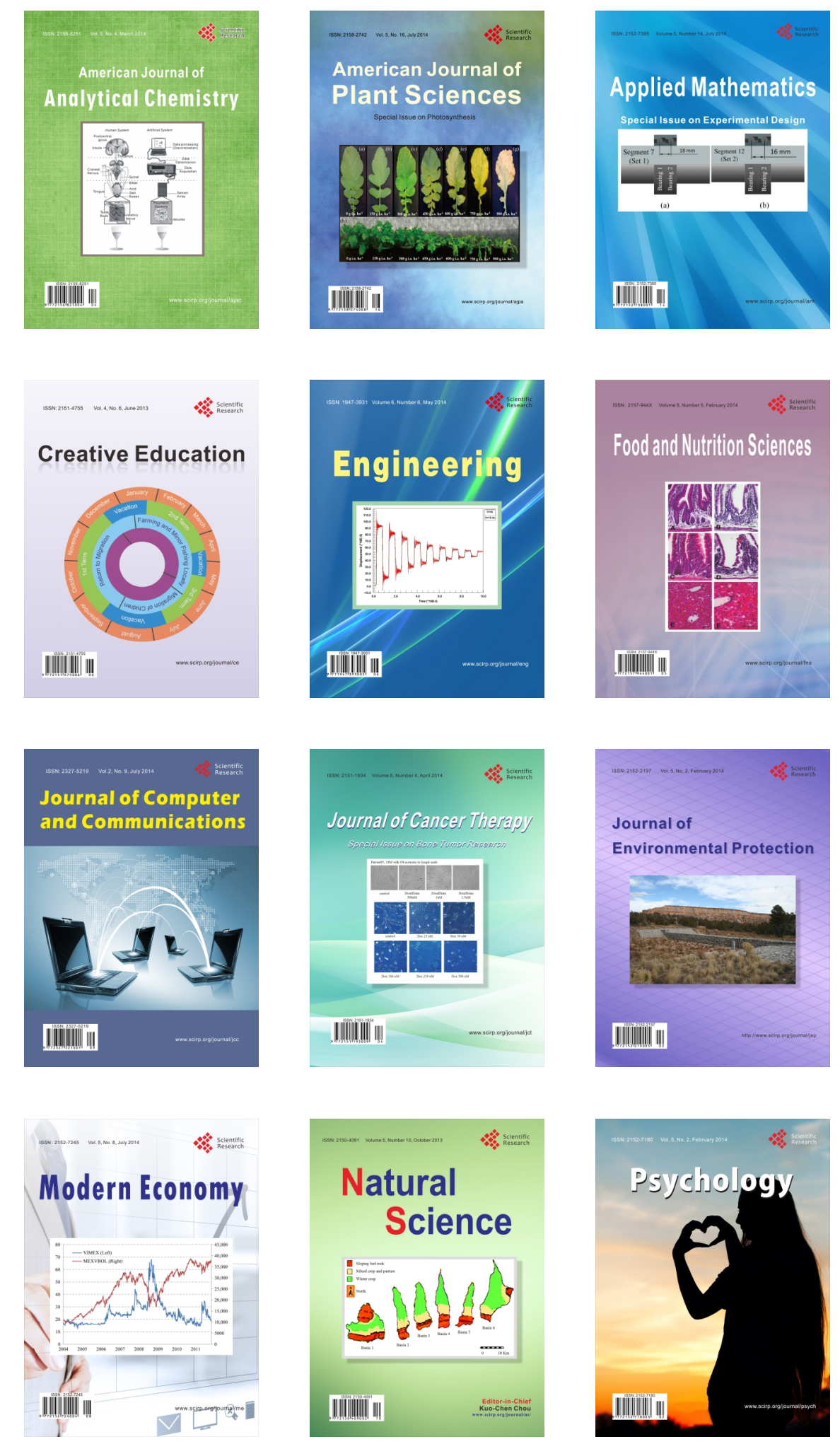